\title{
EVOLUCIÓN HUMANA EN EUROPA: REGISTRO Y DEBATES
}

\author{
Juan Luis ARSUAGA ${ }^{1}$, Ignacio MARTÍNEZ1, José Miguel CARRETERO', \\ Ana GRACIA ${ }^{1}$, Carlos LORENZO' y José María BERMÚDEZ DE CASTRO ${ }^{2}$ \\ ' Dpto. y UEI de Paleontología. Facultad de Ciencias Geológicas. Universidad Complutense de Madrid e Instituto de Geología \\ Económica (CSIC-UCM). 28040-Madrid. \\ 2 Museo Nacional de Ciencias Naturales. CSIC. José Gutiérrez Abascal, 2, 28006-Madrid.
}

\begin{abstract}
Arsuaga, J.L., Martínez, I., Carretero, J.M., Gracia, A., Lorenzo, C. y Bermúdez de Castro, J.M. 1996. Evolución humana en Europa: registro y debates. [Human evolution in Europe: record and debates]. Revista Española de Paleontología, $\mathbf{N}^{\circ}$ Extraordinario, 269-277. ISSN 0213-6937.
\end{abstract}

\begin{abstract}
The three main questions on European human evolution are: the first arrival of humans (who, when and where), the evolutionary pattern along the middle Pleistocene, and the origin of Modern Humans and its relationships with Neandertals. There is no general agreement about the presence of humans in Europe prior to the marine isotopic stage 13, but the recent discovery of lower Pleistocene human fossils and implements in the Gran Dolina site (Sierra de Atapuerca) clearly indicates an earlier settlement. The middle Pleistocene record shows a process of local evolution in Europe that ends with the Neandertals. The Sima de los Huesos (Sierra de Atapuerca) site provides the most complete human sample for this period. In the upper Pleistocene, Neandertals were replaced in Europe by Modern Humans, without evidence of evolutionary continuity. Finally, we analyze the evolutionary relationships between the different human populations of the middle and upper Pleistocene.
\end{abstract}

Keywords: Europe, Pleistocene, Human Evolution, Homo erectus, Homo sapiens, Neandertals.

\section{RESUMEN}

Tres son los principales debates en los estudios de evolución humana en Europa: primer poblamiento de nuestro continente, patrón evolutivo durante el Pleistoceno medio, origen del Hombre moderno y su relación con los neandertales. Hasta la fecha, no existe consenso en admitir la presencia humana en Europa antes del episodio isotópico 13, pero el reciente hallazgo de fósiles humanos e industria lítica en niveles del Pleistoceno inferior del yacimiento Gran Dolina (Sierra de Atapuerca), permite zanjar definitivamente la cuestión. En el Pleistoceno medio tiene lugar, en nuestro continente, un proceso de evolución local que desemboca en los neandertales. Este proceso está especialmente bien documentado en el yacimiento de la Sima de los Huesos de la Sierra de Atapuerca, que ha proporcionado la mayor parte del registro fósil mundial de homínidos para la totalidad del Pleistoceno medio. En el Pleistoceno superior, las poblaciones neandertales fueron reemplazadas en Europa por la humanidad moderna, sin que haya continuidad evolutiva. Por último, se analizan en este trabajo las posibles relaciones filogenéticas entre las diferentes poblaciones humanas del Pleistoceno medio y superior.

Palabras clave: Europa, Pleistoceno, Evolución humana, Homo erectus, Homo sapiens, Neandertales.

\section{EL PRIMER POBLAMIENTO EN EUROPA}

En el año 1994, y en parte coincidiendo con la publicación del hallazgo de una diáfisis de tibia humana en el yacimiento inglés de Boxgrove (Roberts et al., 1994), se ha renovado el interés por la cuestión de los primeros pobladores humanos de Europa. Roebroeks (1994) y Gamble (1994) coinciden en señalar significativas diferencias entre el registro arqueológico y paleoantropológico de los últimos 500.000 años y toda la (presunta) evidencia anterior. El límite (aproximado) correspondería a la extinción del micromamífero Mimomys savini y la aparición de Arvicola terrestris en el registro.

Para Roebroeks y Gamble, los fósiles publicados como humanos de la biozona Mimomys savini son muy fragmentarios y problemáticos (no incluyen un solo diente, por ejemplo), y los objetos líticos se limitan a supuestos "chopping tools" y lascas ("pre-achelenses"), siempre poco numerosos y en con- textos poco claros. Por el contrario, los fósiles incontestablemente humanos de la biozona Arvicola terrestris son abundantes y los utensilios líticos incuestionables (achelenses, con bifaces, en el Pleistoceno medio), y en contextos poco alterados. Este marcado contraste lleva a muchos autores a sospechar que no había presencia humana en Europa hace más de 500.000 años, aunque en los confines orientales del continente, sin embargo, la mandíbula humana de Dmanisi (Georgia) se data en el límite Plio-Pleistoceno (Gabunia y Vekua, 1995). En consecuencia, si se excluye este último, el primer fósil de Europa hasta ahora conocido sería la tibia de Boxgrove, asignada al episodio 13 de la escala isotópica oceánica (-524.000 a -478.000 años). Incluso la antiguiedad de este yacimiento (con Arvicola terrestris cantiana) ha sido discutida. No sólo se carece de evidencia geocronológica alguna que confirme la asignación del yacimiento al episodio 13, sino que los resultados de la aminoestratigrafía sitúan Boxgrove con Swanscombe, en el episodio 11 (-423.000 a -362.000 años) (Bowen y Sykes, 1994). 
Un yacimiento que reúne condiciones para contrastar la mencionada hipótesis del poblamiento "reciente" (no mucho más de 500.000 años) de Europa, lo constituye el denominado Gran Dolina, en la Sierra de Atapuerca. Aquí se han encontrado fósiles humanos y utensilios líticos en niveles del Pleistoceno inferior, con Mimomys savini (Carbonell y Rodríguez, 1994; Carbonell et al., 1995), lo que no deja lugar a dudas sobre un poblamiento muy antiguo de Europa occidental.

\section{REGISTRO FÓSIL DEL PLEISTOCENO MEDIO EUROPEO Y EL ORIGEN DE LOS NEANDERTALES}

El registro fósil europeo se divide habitualmente entre fósiles del Pleistoceno medio y del Pleistoceno superior. Dentro del Pleistoceno medio (desde -780.000 a -128.000 años), pueden establecerse otras subunidades cronológicas con un alto grado de incertidumbre, debido a la limitada resolución que, por el momento, ofrece la bioestratigrafía y la arqueología para este lapso temporal y la escasa (o casi siempre nula) disponibilidad de dataciones geocronológicas en los yacimientos. En gran medida, estas divisiones descansan, por lo tanto, en criterios morfológicos derivados de los propios fósiles humanos, o mejor, en las polaridades establecidas a partir de fósiles extraeuropeos (anteriores en el tiempo) y fósiles (neandertales) del Pleistoceno superior europeo.

En cualquier caso, la mayor parte de los autores (ver Hublin, 1988, por ejemplo) aceptan (con algunas variaciones), un esquema que establece cuatro grupos "morfo-cronológicos" de fósiles europeos mesopleistocenos. En esencia, estos grupos se diferencian por la paulatina desaparición de rasgos primitivos y la cada vez mayor presencia de caracteres derivados neandertales. Se considera, por tanto, que el registro fósil refleja un proceso de evolución local en Europa que, a partir de pobladores venidos de Asia o de Africa (a través del Oriente Próximo), dio finalmente lugar a los neandertales.

I) El grupo de fósiles más antiguos incluiría la tibia de Boxgrove y la mandíbula de Mauer (Alemania) (Fig. 1). En

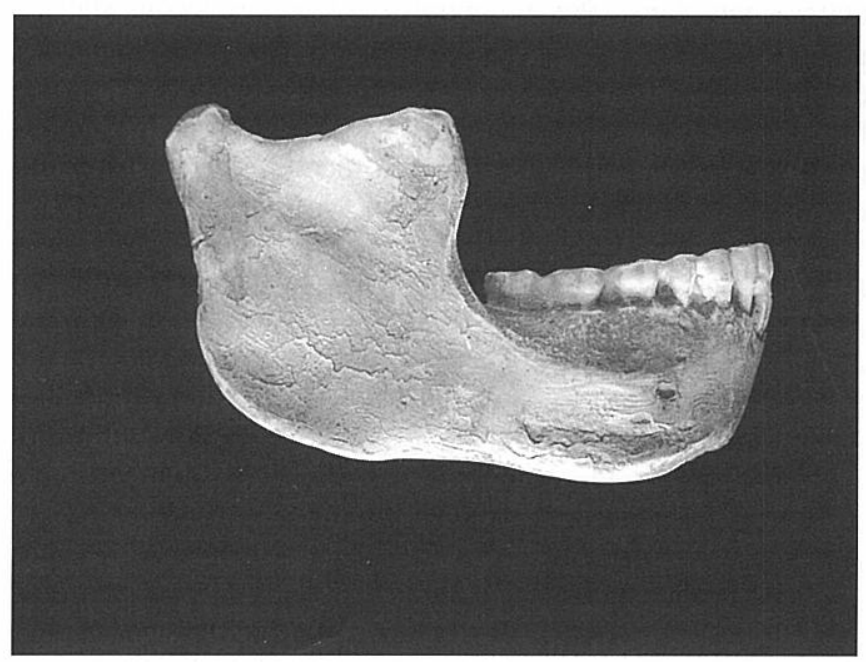

Figura 1. Mandíbula de Mauer (molde). esta última no se aprecian rasgos indiscutiblemente neandertales, y la primera no aporta información relevante a este respecto.

II) Un grupo más moderno abarcaría los restos de Bilzingsleben (Alemania), Vértesszöllös, Arago y, con muchas dudas en cuanto a la cronología, Petralona. Los fragmentos craneales de Bilzingsleben (Fig. 2) han sido considerados muy primitivos por algunos autores, que incluso los han atribuido a Homo erectus. Sin embargo, en nuestra opinión, las características del fragmento lateral de torus supraorbitario no se corresponden con las de la citada especie, y el fragmento glabelar, aunque muy robusto y proyectado, presenta una morfología neandertal (Fig. 2a).

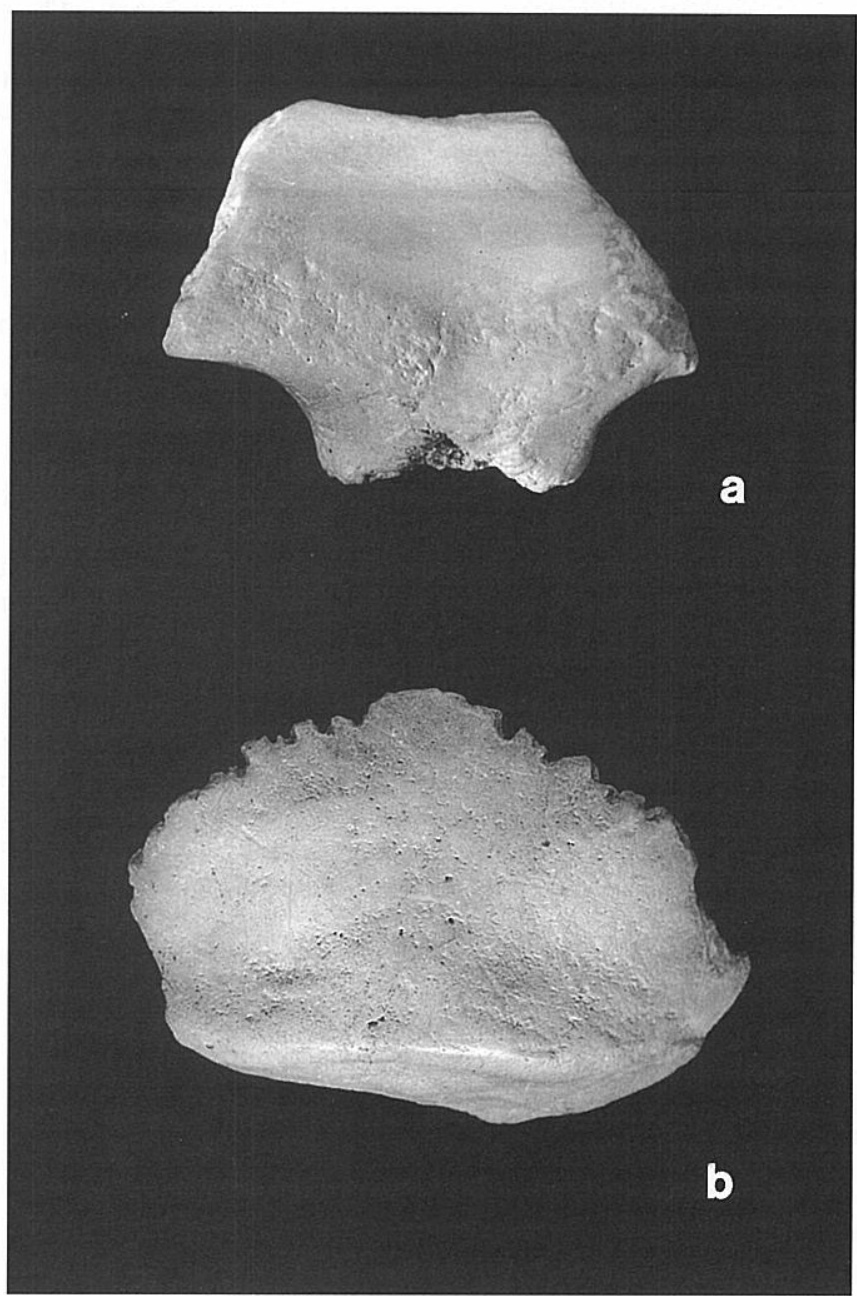

Figura 2. Restos de Bilzingsleben: a) Región glabelar del frontal (molde). b) Occipital (molde).

El occipital de Vértesszöllös (Hungría) muestra un torus occipital peculiar y único, que se caracteriza por su gran desarrollo en altura, ascendiendo a lo largo de la escama occipital hasta aproximarse mucho al lambda. Por otro lado, recientemente se ha apuntado una edad más moderna (dentro del Pleistoceno medio) para este fósil (Stringer, 1992).

El más abundante registro de Arago (Francia), incluye, entre otros restos, dos mandíbulas, un parietal y un esqueleto 
facial completo, aunque deformado (Fig. 3). Respecto de las mandíbulas, podrían esbozarse en ellas algunos rasgos neandertales (especialmente en Arago 2), y en cuanto al macizo facial (Arago 21), y pese al aplastamiento post-mortem que en gran medida lo deforma, nosotros apreciamos una morfología maxilo-malar que refleja un buen grado de proyección de la parte media (o nasal) de la cara. Este tipo de prognatismo es muy acusado en los neandertales y se traduce, entre otras manifestaciones, en un maxilar inflado (sin fosa canina) y con orientación sagital u oblicua (maxilar extendido).

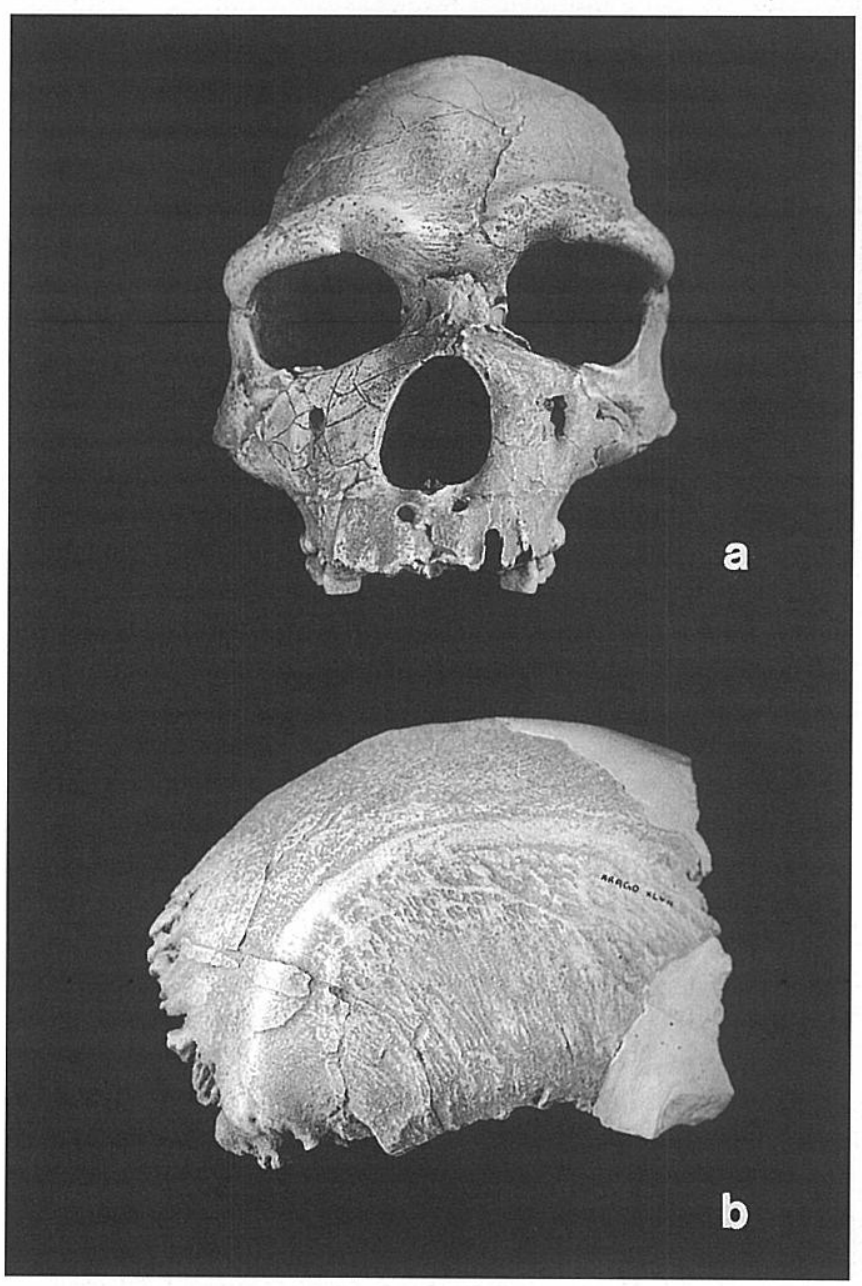

Figura 3. Restos craneales de Arago: a) Esqueleto facial de Arago 21 (molde). b) Parietal derecho Arago 47 (molde).

Por último, el cráneo de Petralona (Grecia), aunque muy bien conservado, carece de contexto claro. Su morfología incluye un torus occipital de morfología no neandertal y un esqueleto facial que ha dado lugar a diferentes interpretaciones. El torus supraorbitario es más semejante al de los neandertales que el de Arago 21, que, a su vez, recuerda al de los fósiles africanos mesopleistocenos Bodo y Broken Hill (= Kabwe). Sin embargo, Bodo se aproxima particularmente a Petralona en su gran abertura nasal y maxilar inflado, con un margen inferior que, en norma frontal, desciende recto hacia el borde alveolar (como en los neandertales). Sin embargo, la parte media del macizo facial está claramente más proyectada en Petralona que en Bodo. Una forma de cuantificar este tipo de prognatismo es el ángulo zigomaxilar o subespinal de Howells (1973). La Tabla 1 muestra que los primeros fósiles de Homo exhiben una cara media aplanada transversalmente (KNM-ER 1470, KNM-ER 1813, OH 24, SK-847, KNM-ER 3733). El mayor grado de prognatismo se da entre los neandertales, aunque Broken Hill y los fósiles europeos del Pleistoceno medio entran dentro de su rango (Arago, Cráneo 5 de la Sima de los Huesos), o lo superan sólo ligeramente (Petralona).

III) El tercer grupo del Pleistoceno medio europeo estaría constituido por los fósiles de la Sima de los Huesos de la Sierra de Atapuerca y los restos de Steinheim, Reilingen y Swanscombe. El registro de la Sima de los Huesos es excepcional por haberse acumulado en este lugar más de treinta y dos cadáveres humanos, lo que hace posible emprender, por primera vez, un estudio de la paleobiología de una población humana del Pleistoceno medio y abordar aspectos tales como la variabilidad, dimorfismo sexual, desarrollo, patologías, etc. Para calibrar su importancia basta recordar que, en cuanto al esqueleto postcraneal, el hipodigma actualmente disponible representa ya más de las tres cuartas partes del registro mundial mesopleistoceno. Esta muestra es, por supuesto, una referencia obligada para cualquier análisis evolutivo.

Morfológicamente, los fósiles de la Sima de los Huesos (España) exhiben numerosos rasgos primitivos (no presentes en los neandertales) (Arsuaga et al., 1993). El hueso occipital (bien representado en la colección y muy homogéneo en sus características), presenta un torus recto con una superficie suprainíaca plana o poco deprimida, rugosa (o porosa), amplia y elevada en sentido inion-lambda (Fig. 4a). Como luego se verá, esta morfología es intermedia entre las observadas en Vértesszöllös y en Reilingen o Swanscombe (Fig. 5b). Por otro lado, y entre muchos rasgos primitivos del neurocráneo y del esqueleto facial, se aprecia una morfología del torus supraorbitario derivada (en sentido neandertal), así como marcada proyección de la cara media (Tabla 1; Fig. 4b). No obstante, uno de los individuos (AT-404; Fig. 4c) presenta fosa canina, por lo que podría haber polimorfismo en el seno de la muestra de Atapuerca (y del Pleistoceno medio) en cuanto a morfología maxilar. También se observa con claridad, en la amplia serie de restos mandibulares, la asociación de rasgos primitivos y neandertales (éstos en relación, una vez más, con la proyección medio-facial, y el adelantamiento de la serie dentaria). En la muestra de la Sima de los Huesos las proporciones entre la dentición anterior (I1P3) y posterior (P4-M3), v. gr. la relación P3/P4, son únicas (autapomorfía) en el registro de los homínidos. Mientras que la dentición anterior muestra una reducción comparable a la de otras poblaciones europeas del Pleistoceno medio y los neandertales, el segmento posterior alcanza un grado de reducción mucho más marcado, casi idéntico al de las poblaciones modernas (lo que se interpreta como un caso de paralelismo). La mayor parte de los caracteres dentales de los homínidos de la Sima de los Huesos son derivados y compartidos, bien con otros homínidos europeos del Pleistoceno medio y con los neandertales (taurodontismo radicular), bien con estos homínidos y las poblaciones modernas (ausencia de cíngulo y presencia de una raíz en premolares inferiores). El esqueleto postcraneal muestra cierto número de rasgos compartidos con los neandertales, pero en este caso es más difícil 


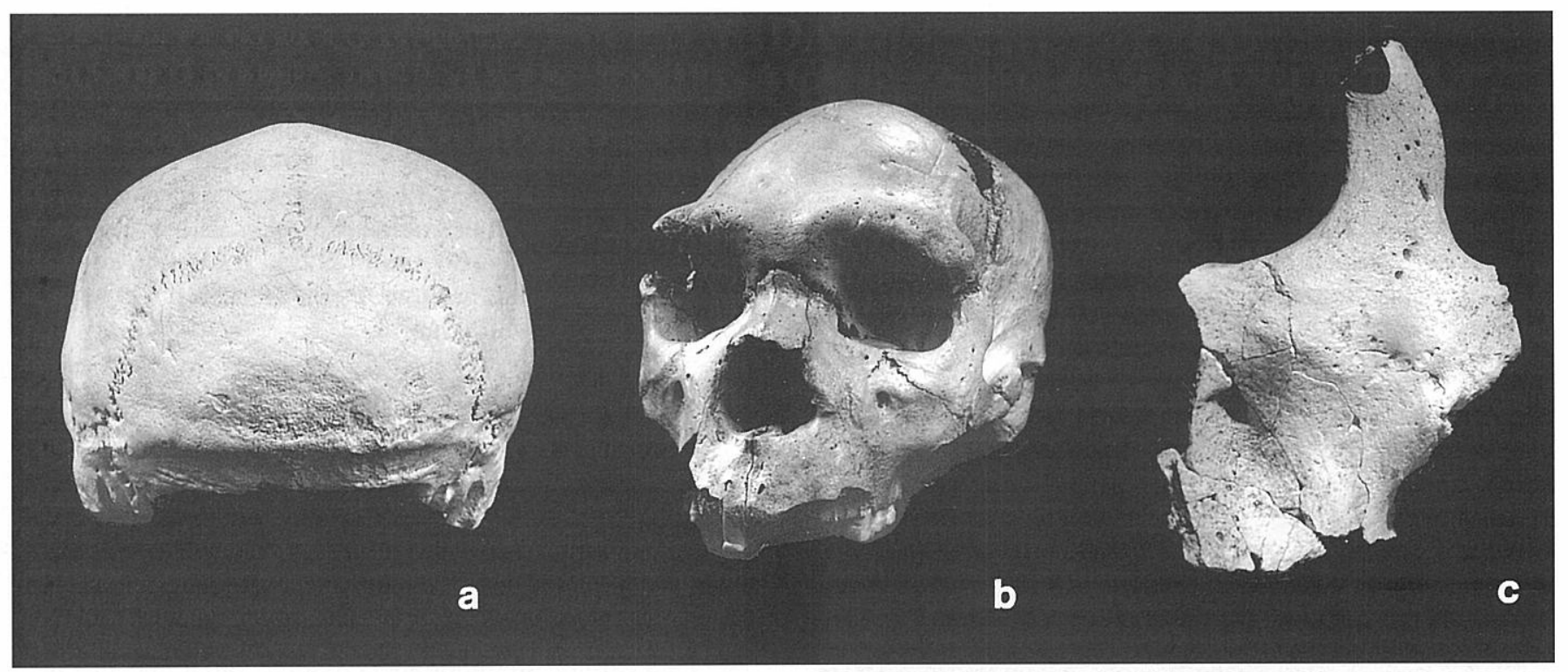

Figura 4. Fósiles de la Sima de los Huesos (Sierra de Atapuerca, Burgos): a) Cráneo 4. b) Cráneo 5. c) Maxilo-malar izquierdo AT-404.

establecer polaridades debido a la escasez de fósiles postcraneales en el registro del Pleistoceno inferior y medio.

El cráneo de Steinheim (Alemania) es de difícil interpretación, debido a las pérdidas y deformaciones sufridas post-mortem (Fig. 5a). La morfología occipital parece comparable a la de la muestra de la Sima de los Huesos, y en el esqueleto facial se observa la presencia de fosa canina y un maxilar flexionado (en lugar de extendido). Estos dos rasgos faciales no se encuentran en ningún otro fósil del registro europeo hasta el Paleolítico superior, con la excepción del ejemplar de Atapuerca antes mencionado. No obstante, la deformación sufrida por Steinheim podría haber exagerado la flexión del maxilar, y AT-404 es un resto fragmentario, que

\begin{tabular}{|c|c|c|}
\hline FOSIL & $\begin{array}{c}\text { Ángulo Subespinal } \\
\text { SSA }\end{array}$ & FUENTE \\
\hline KNM-ER 1470 & 161 & Rightmire (1993) \\
\hline $\mathrm{OH} 24$ & 143 & " " \\
\hline KNM-ER 1813 & 143 & $"$ \\
\hline SK-847 & (147) & Autores \\
\hline KNM-ER 3733 & 146 & Autores 1 \\
\hline Bodo & 139 & Autores \\
\hline Arago 21 & (111) & Autores 1 \\
\hline Broken Hill & 117 & Autores \\
\hline Petralona & 119 & Stringer (1983) \\
\hline Atapuerca Cr. 5 & 111,2 & Autores \\
\hline Dali & 123 & Wu y Wu (en Etler, 1994) \\
\hline Jebel Irhoud & 122 & Howells $(1975)^{1}$ \\
\hline Qafzeh 6 & 134 & Howells (1975) \\
\hline Skhül 5 & (124) & $"$ " \\
\hline Afalou 5 & 127 & " " \\
\hline Predmost 3 & 121 & Autores 1 \\
\hline Mladec 1 & 126 & Autores \\
\hline Zhoukoudian Upper Cave 101 & 132 & Autores 1 \\
\hline Neandertales & $103,5-117(\mathrm{~N}=10)$ & Autores ${ }^{2}$ \\
\hline Homo sapiens actual & $120,05-137,6$ & Howells $(1973)^{3}$ \\
\hline
\end{tabular}

1. Medidas sobre moldes.

2. Los valores proceden de diversas fuentes bibliográficas y mediciones de los autores sobre originales o moldes.

lins (masculinas + femeninas) de 17 poblaciones humanas modernas. (). Valores aproximados.

Tabla 1. Valores del Ángulo Subespinal (SSA; según Howells, 1973) en fósiles de Homo y poblaciones modernas. todavía no permite conocer íntegramente la morfología facial del individuo. Otro carácter en el que Steinheim parece sorprendentemente "moderno" (salvo que se halle también en esto afectado por deformación póstuma), es en la reducida anchura biauricular, que indica una base del cráneo estrecha, incluso para un cráneo de tan reducidas dimensiones. En cuanto al torus supraorbitario Steinheim ya presenta una morfología neandertal.

A pesar de la poca información disponible sobre la calvaria incompleta de Reilingen (Alemania) (Czarnetzki, 1991), a nuestro juicio es comparable a los parietales y occipital de Swanscombe (Inglaterra) (Fig. 5b). En ambos individuos hay una depresión suprainíaca asociada a un torus deprimido medialmente y con dos proyecciones laterales. Esta morfología claramente precede a la propiamente neandertal y es más derivada que la de Atapuerca o Steinheim, por lo que resulta difícil aceptar la atribución de Swanscombe a un episodio isotópico tan antiguo como el 11. Por otro lado, el perfil transversal del neurocráneo en norma posterior muestra en ambos fósiles unas paredes verticalizadas ("forma de casa"), que puede representar un estado intermedio entre la morfología primitiva, con la máxima anchura en el temporal ("forma de tienda de campaña"; ver p.ej. Fig. 4a), y el perfil redondeado ("forma en bomba"; ver p.ej. Fig. 7c) de los neandertales.

IV) El último grupo "morfo-cronológico" estaría compuesto por fósiles atribuidos al final del Pleistoceno medio (episodios 6 y 7). Los más significativos son los procedentes de los yacimientos de Biache-Saint-Vaast, La Chaise Suard (Francia) y Ehringsdorf (Alemania). Este último se asignaba tradicionalmente al episodio 5e (comienzos del Pleistoceno superior), pero según las últimas fechas obtenidas por series de uranio sobre los dos travertinos de la secuencia de Erhingsdorf, los fósiles humanos podrían corresponder al episodio 7 (Blackwell \& Schwarz, 1986).

Este grupo de fósiles presenta características básicamente neandertales en las regiones anatómicas conservadas, por lo que puede concluirse que los neandertales ya estaban presentes en Europa a finales del Pleistoceno medio. 


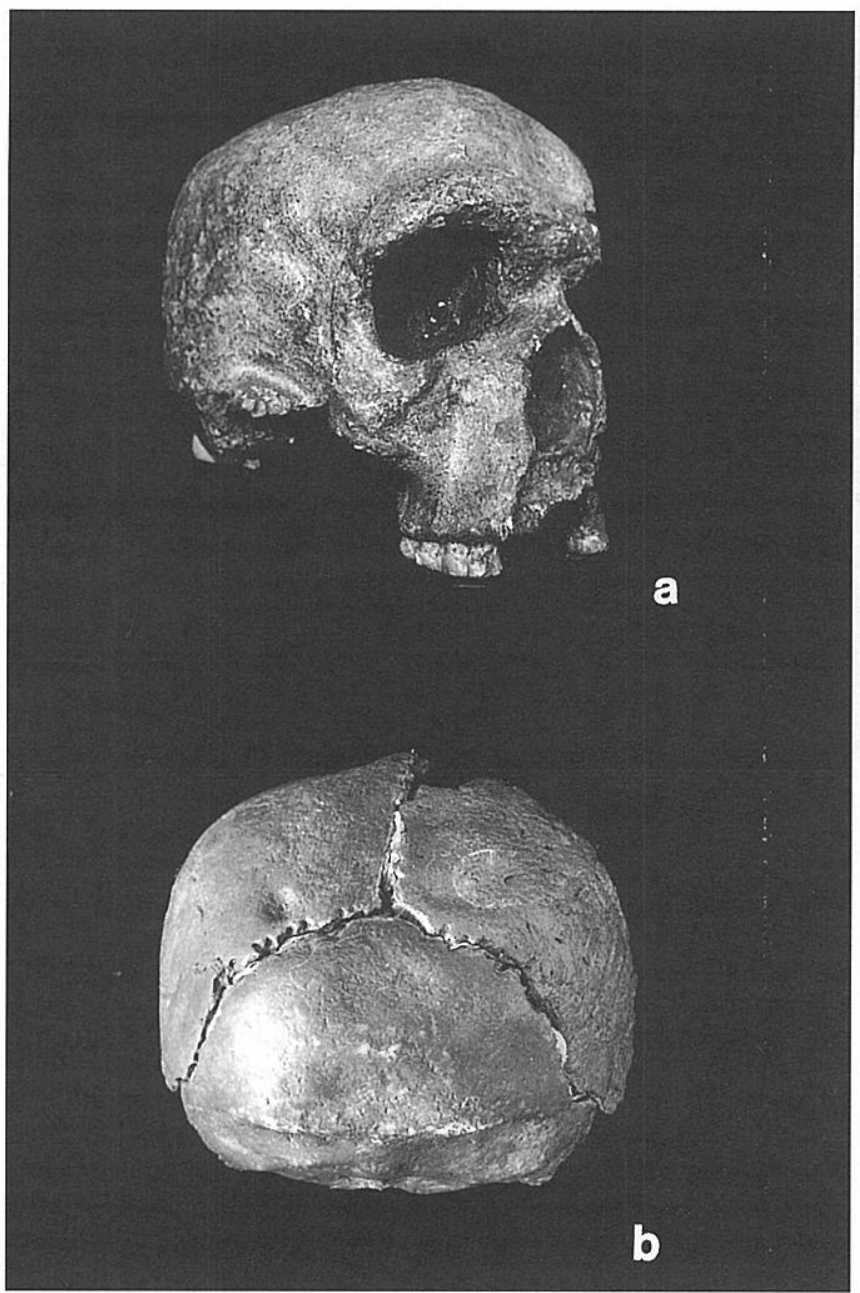

Figura 5. a) Cráneo de Steinheim (molde). b) Vista posterior del occipital y parietales de Swascombe (molde).

Además de los fósiles de Atapuerca hay otros fósiles españoles atribuidos al Pleistoceno medio. Así, los dos dientes y el húmero de la cueva de Lezetxiki, conservado en su integridad y de cronología discutida (procede del nivel VII de esta cueva, inferior a los niveles "musterienses"). Otro fósil del registro español, la mandíbula de Bañolas (Fig. 6), durante mucho tiempo considerada del Pleistoceno medio, ha sido datado recientemente por series de uranio en torno a los 45.000 años (Julià \& Bischoff, 1991). Esta nueva cronología es difícilmente conciliable con la ausencia de apomorfías neandertales en el resto fósil, si bien ignoramos hasta qué punto su morfología puede estar afectada por la misma disfunción responsable del desgaste dentario, tan anormal, que presenta. Por último, en el yacimiento mesopleistoceno de Pinilla del Valle han sido hallados dos molares humanos (Alférez, 1985).

\section{NEANDERTALES Y HOMBRES MODERNOS EN EL PLEISTOCENO SUPERIOR}

Los primeros dos tercios (aproximadamente) del registro fósil europeo del Pleistoceno superior corresponden a los

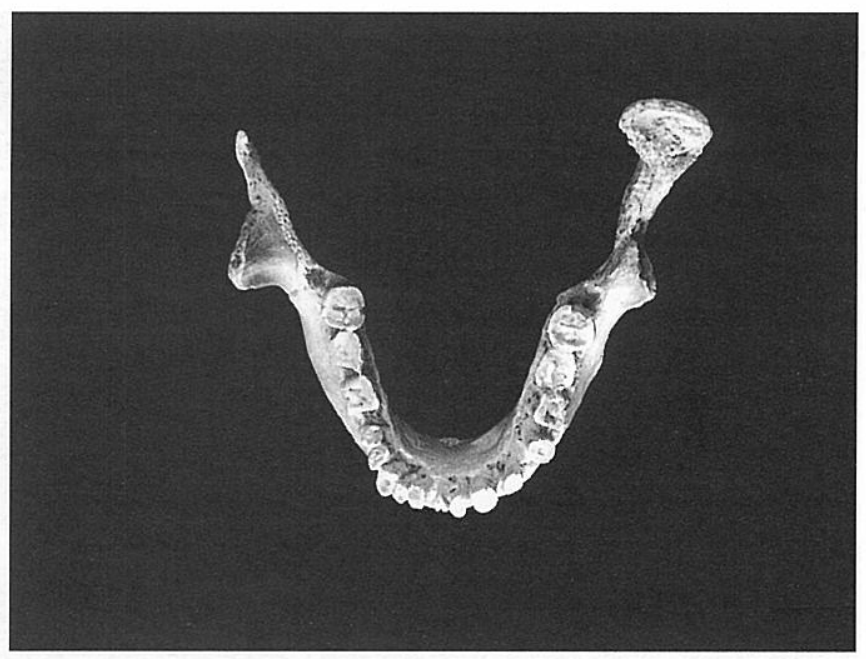

Figura 6. Mandíbula de Bañolas (Molde)

neandertales, sin que, pese a los muchos estudios realizados, puedan discernirse claramente cambios morfológicos importantes a lo largo del tiempo. Durante este período el registro de los neandertales se extiende al Oriente Próximo e incluso al Asia Central, y va siendo cada vez más abundante en lo que se refiere a la Península Ibérica. El registro ibérico incluye los fósiles procedentes de los yacimientos de Agut, Axlor, Cova Negra (que en el pasado se situaba erróneamente en el Pleistoceno medio), Gibraltar (Devil's Tower y Forbes Quarry), La Carigüela, Valdegoba, Vilafamés (que también podría corresponder a finales del Pleistoceno medio), Zafarraya, Gabasa, Mollet I y Los Casares (Fig. 7).

En aquellos yacimientos europeos donde existen secuencias estratigráficas continuas para la segunda mitad del Pleistoceno superior se observa, bien una sustitución abrupta de las industrias del Paleolítico medio (musteriense) por las primeras del Paleolítico superior (auriñaciense), o bien una facies interpuesta con características comunes a ambas, el chatelperroniense de algunos yacimientos de la cornisa cantábrica y del oeste y centro de Francia (un equivalente en la Europa central podría ser el szeletiense y en Italia el uluziense). Dos ejemplos muy bien estudiados del primer caso (musteriense truncado) lo tenemos en L'Arbreda y en Abric Romaní, donde la sustitución se sitúa hace $c .40 .000$ años (Bischoff et al., 1988, 1994). Para el cantábrico el auriñaciense más antiguo se data en El Castillo hace c. 39.000 años (Bischoff et al., 1989), aunque siempre cabe la posibilidad de un comienzo más reciente del registro del Paleolítico superior en la España meridional.

Los fósiles humanos encontrados hasta la fecha en contexto musteriense en Europa son neandertales, y los que proceden de niveles del Paleolítico superior corresponden al tipo humano moderno. En contexto chatelperroniense se sitúan los fósiles de Arcy-sur-Cure (dientes aislados) y el esqueleto parcialmente conservado de Saint Césaire (Vandermeersch, 1984). En este último caso no cabe duda de que se trata de un individuo neandertal, datado en hace unos $36.300 \pm 2.700$ años (Mercier et al., 1991). Tal fecha no deja margen cronológico para una posible transición de los neandertales a los hombres modernos en Europa occidental, admitiendo que 


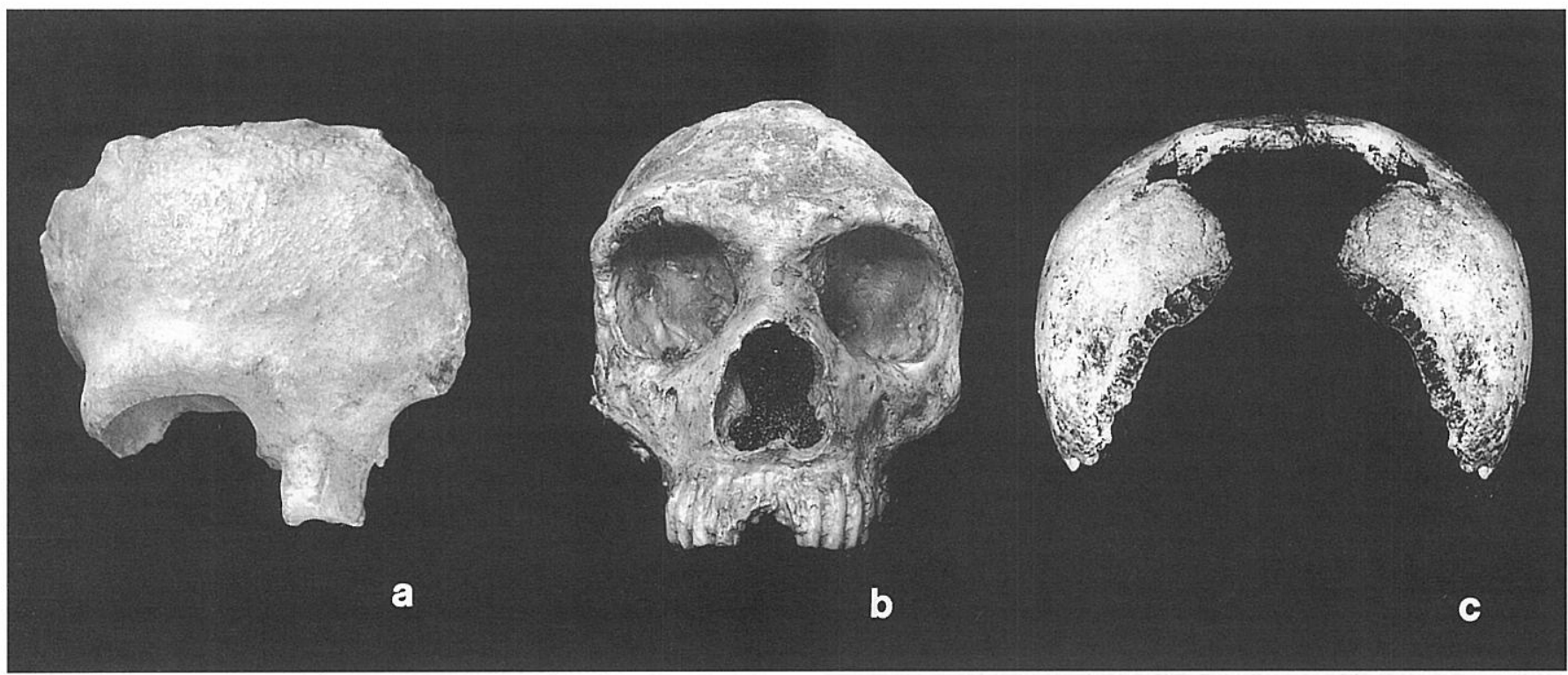

Figura 7. Restos neandertales de la Península Ibérica: a) Frontal de La Carigüela (molde). b) Cráneo de Gibraltar 1 (molde). c) Reconstrucción especular del perfil en norma posterior del parietal de Cova Negra.

éstos sean los autores de las primeras industrias del Paleolítico superior. Un fósil interesante a este respecto es el frontal de Hahnöfersand, que, aunque carece de contexto, ha sido datado directamente por aminoácidos y radiocarbono en 36.000 años (Bräuer, 1981). A nuestro entender, debe encuadrarse, por la morfología supraorbitaria, entre los hombres modernos.

Desgraciadamente no se dispone aún de fósiles humanos asociados a las primeras industrias del auriñaciense en Europa occidental. Los esqueletos del yacimiento de CroMagnon podrían ser desde auriñaciense final (Gambier, 1989) hasta perigordiense final (Frayer, 1992). En este último caso habría un lapso temporal de 12.000 años desde Saint-Césaire hasta Cro-Magnon. Fragmentos de dos individuos, un adulto y un niño de 4 ó 5 años, fueron hallados en el nivel 18 (auriñaciense) de El Castillo. El paradero actual de estos restos es desconocido, pero Garralda (1989) proporciona datos de los fósiles procedentes de un informe de Vallois (del año 1935, no publicado). Al parecer, el individuo adulto estaba representado por tres pequeños y robustos fragmentos craneales y un segundo molar inferior derecho relativamente grande (aunque, según Garralda, dentro de los rangos de los fósiles europeos del Paleolítico superior). En Europa central, la serie esquelética de Mladeč (Moravia) se data hacia los 32-30.000 años (Vlček, 1991). En nuestra opinión, estos restos no son transicionales sino anatómicamente modernos (aunque robustos).

\section{TAXONOMÍA Y FILOGENIA}

Los estudios cladísticos muestran que los neandertales están demasiado derivados para dar lugar a los "hombres modernos" (Rak, 1993), lo que no excluye la posibilidad de mestizaje (si no se habían producido barreras genéticas infranqueables). En todo caso, el argumento más persuasivo en contra del esquema neandertales -> "hombres modernos" en Europa es cronológico: estos últimos están presentes en el levante mediterráneo (Qafzeh y Skhūl) y en Africa del Sur (Klasies River Mouth) hace unos cien mil años, por lo que no han podido evolucionar a partir de los neandertales 60.000 años más tarde.

Las dos unidades taxonómicas más fáciles de caracterizar en Paleontología Humana son la especie humana actual (por razones obvias) y los neandertales (en este caso debido a la amplitud del registro). La cuestión de si deben considerarse subespecies o especies diferentes (Homo sapiens y Homo neanderthalensis) es, en cambio, menos asequible. Refutada, a nuestro entender, la hipótesis de una evolución anagenética de neandertales a modernos, la ausencia de híbridos parece inclinar la balanza a favor del aislamiento reproductor. Las barreras, no obstante, podrían haber sido culturales y no biológicas. Neandertales y hombres modernos

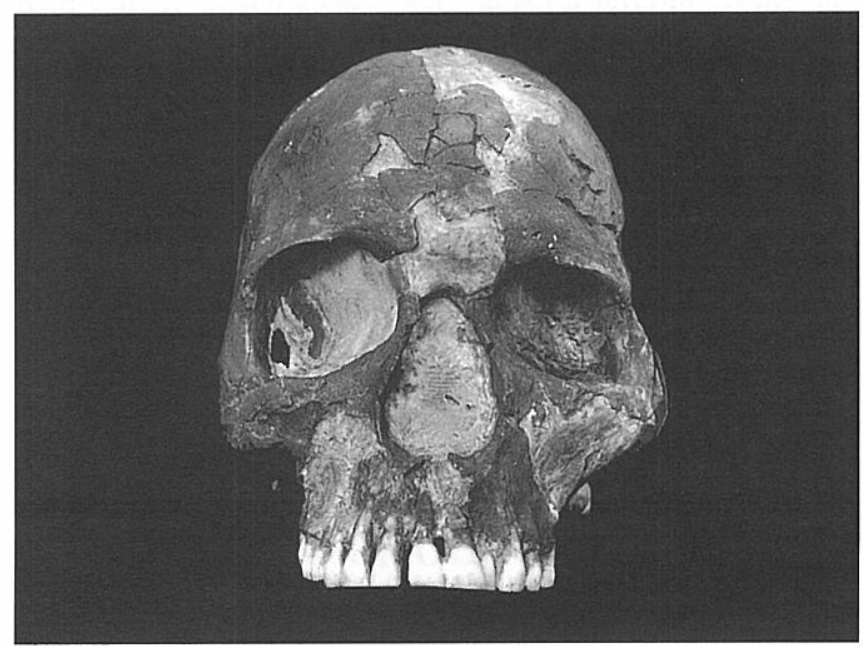

Figura 8. Cráneo de Qafzeh 9 (molde). 
compartieron en Oriente Próximo el mismo tipo de tecnología (musteriense), y tal vez convivieron en un espacio geográfico muy limitado. El yacimiento de Tabun ha sido datado también en torno a los 100,000 años (McDermott et al., 1993), aunque algunos autores (Bar-Yosef y Pilbeam, 1993) opinan que la mandíbula (aislada) de aspecto moderno (TII) pertenece al nivel antiguo, contemporáneo de Skhūl y Qafzeh (nivel C), y el esqueleto neandertal femenino a un nivel más reciente (nivel B). Por otro lado, el chatelperroniense europeo parece indicar cierta efímera influencia tecnológica de los hombres modernos sobre los neandertales.

En pocas palabras, la evidencia es compatible tanto con un modelo de dos especies distintas que comparten el mismo tipo de tecnología (Stringer y Gamble ,1993), o con el de dos poblaciones morfológicamente diferenciadas tras un largo período de separación geográfica, aisladas genéticamente, pero más por mecanismos culturales que biológicos, que cuando se ponen en contacto intercambian información pero pocos genes, y que finalmente compiten ecológicamente con supervivencia de una de ellas y extinción de la otra.

En los últimos años, algunos autores han adoptado una división de los fósiles del Pleistoceno medio en dos grandes grupos. Por un lado los restos del Extremo Oriente que formarían el hipodigma de la especie Homo erectus (en sentido restringido). Este conjunto abarca todos los fósiles del registro de Java, desde los primeros (que podrían remontarse a 1.800.000 años: Swisher et al., 1994) hasta los más recientes de Ngandong, y los fósiles chinos de Lantian, Zhoukoudian y Hexian. Por otro lado se considera un conjunto de fósiles mesopleistocenos europeos (Mauer, Arago, Atapuerca, Bilzingsleben, Petralona, Vértesszöllös, Steinheim y Swascombe), africanos (Salé, Bodo, Ndutu, Broken Hill) y asiáticos (Jinniu Shan, Dali, Maba, tal vez Yunxian y Narmada), que no son propiamente Homo erectus, presentan un rango de capacidad craneal intermedio entre el de esa especie y la nuestra, y están lo bastante poco diferenciados como para no ser incluidos con los neandertales o los hombres modernos. Estos fósiles han sido denominados informalmente Homo sapiens "arcaicos" (Stringer, 1992) y habrían dado lugar en Europa a los neandertales a finales del Pleistoceno medio, con fósiles como La Chaise Suard, Ehringsdorf o Biache (Stringer, 1992). En un proceso evolutivo similar, habría aparecido en Africa el Homo sapiens "anatómicamente moderno" (nuestra propia subespecie), con antecedentes próximos en fósiles del Pleistoceno medio final como Jebel Irhoud, Ngaloba y Omo Kibish. El papel que en todo este esquema evolutivo corresponde a los Homo sapiens "arcaicos" de Asia está aún por determinar. Sin embargo, si se reconoce a los neandertales el estatus de especie, los Homo sapiens "arcaicos" tendrían que recibir un nuevo nombre específico, para el que se ha rescatado el de Homo heidelbergensis.

La relación evolutiva entre Homo erectus y Homo sapiens es todavía controvertida. Cuando Howells (1980) publicó su extensa revisión de Homo erectus, esta especie se reconocía por la generalidad de los autores como antecesora de Homo sapiens, siguiéndose un esquema evolutivo anagénetico. La cuestión a determinar entonces era dónde emplazar la difusa línea de división entre ambas especies (o grados evolutivos) y, en consecuencia, qué fósiles asignar a una u otra. Si se situara a finales del Pleistoceno medio, entonces los llamados Homo sapiens "arcaicos" serían en realidad
Homo erectus, una especie que se habría extendido por los tres continentes del Viejo Mundo, y cuyos primeros fósiles se encontrarían en el Pleistoceno inferior africano. Más recientemente, Wood (1991) reúne a estos últimos en la especie Homo ergaster.

A partir sobre todo del estudio cladístico de Andrews (1984), numerosos autores han pasado a considerar que la especie Homo erectus (en el sentido restringido antes mencionado) no puede ser antecesora de Homo sapiens. Sin embargo, esta hipótesis debería ser contrastada con los fósiles asiáticos que parecen, a primera vista, mejores candidatos a representar formas transicionales entre $H$. erectus y $H$. sapiens "arcaicos": Zhoukoudian 5 (considerado por los autores chinos más reciente que el resto de la muestra mesopleistocena de este yacimiento), los dos cráneos de Yunxian y el fósil indio de Narmada. Además, está aún por determinar si los fósiles del hipodigma de Homo erectus preceden en el tiempo a los Homo sapiens "arcaicos". A este respecto sería especialmente relevante establecer la cronología de los fósiles de Ngandong, porque su edad podría remontarse desde -600.000 años hasta el Pleistoceno superior (y ser incluso contemporáneos de los primeros anatómicamente modernos). Vale la pena destacar que entre los proponentes de la hipótesis del origen africano reciente de la poblaciones humanas modernas, G. Bräuer no ve problemas en una transición $H$. erectus / H. sapiens "arcaicos" en Asia oriental, mientras C.B. Stringer no cree posible tal evolución (Stringer y Bräuer, 1994). En este último caso el continente asiático habría recibido tres oleadas migratorias desde Africa: $H$. erectus, $H$. sapiens "arcaicos" y $H$. sapiens modernos.

Volviendo a Europa, en la medida en que se amplía el registro fósil mesopleistoceno (muy especialmente gracias a la Sima de los Huesos) se va apreciando que el proceso de evolución local que finalizó con los neandertales tiene raíces muy antiguas. Es muy posible que todos los fósiles del Pleistoceno medio europeo anteriormente citados sean posteriores a la cladogénesis neandertales / hombres modernos, por lo que en sentido cladístico estricto todos ellos se deberían agrupar con los neandertales, y todos sus contemporáneos africanos con los hombres modernos (aunque, de hecho, no lo sean en su anatomía). En tal sentido, ya hace tiempo que Tattersall (1986) argumentaba que existe una tendencia a subestimar el número de especies en el registro fósil de la evolución humana. Este autor observaba que especies estrechamente relacionadas de primates sólo muestran diferencias morfológicas leves, y a veces en partes anatómicas que no conservan los fósiles. Para Tattersall, aunque agrupar muchos fósiles en pocas especies pueda parecer "moderno", en tanto que se aplica un criterio anti-tipológico, se corre el riesgo de perder de vista la diversidad morfológica que el registro fósil muestra. La consecuencia del razonamiento de Tattersall sería la multiplicación de taxones de homínidos en el Pleistoceno medio:

- Homo erectus, en sentido restringido con los fósiles asiáticos arriba mencionados.

- Homo heidelbergensis, taxón ahora referido a fósiles europeos del Pleistoceno medio con algún rasgo derivado en sentido neandertal.

- Homo neanderthalensis, para los últimos fósiles europeos mesopleistocenos y los neandertales del Pleistoceno superior. 
- Homo rhodesiensis, fósiles africanos mesopleistocenos con pocas apomorfías de la especia humana actual.

- Homo sapiens. Nuestra especie. Sus fósiles más antiguos podrían remontarse al Pleistoceno medio final africano.

Otra posibilidad, sería acomodar las cuatro últimas unidades como subespecies dentro de Homo sapiens. El grupo de los Homo sapiens "arcaicos" se dividiría entre H. s. heidelbergensis, H. s. rhodesiensis y los fósiles asiáticos (para los que no se ha propuesto nombre). En todo caso, se reconocerían, al menos, dos líneas evolutivas divergentes que habrían evolucionado en Europa y Africa a partir de un antepasado africano, que no sería Homo erectus s.s. El ancestro común a $H$. sapiens y $H$. erectus habría vivido en Africa en el Plioceno superior (hace más de 1.800 .000 años si se confirman las dataciones recientemente publicadas de los primeros fósiles de Java).

En resumen, la evidencia paleontológica es compatible con un modelo de evolución ramificada para el Pleistoceno medio y superior. Esta división de linajes parece más de origen geográfico que diversificación ecológica (especialización en nichos diferentes en condiciones de simpatría), si bien cada uno de los "stocks" de población hubo sin duda de adaptarse a recursos naturales y condiciones climáticas en parte diferentes ( inferior, ambos tipos de diversificación parecen haber tenido lugar). Finalmente, en la última parte del Pleistoceno superior se produjo un brusco descenso de la diversidad morfológica, que básicamente se interpreta como el resultado de la desaparición (diezmado) de todas las líneas evolutivas menos la que conduce a la especie humana actual, que a partir de un centro único de origen habría reemplazado a las otras (con escasa o irrelevante absorción de genes).

\section{AGRADECIMIENTOS}

Este trabajo se incluye dentro de los proyectos DGYCIT PB90-0126-C03 y PB93-0066-C03. Las excavaciones en los yacimientos pleistocenos de la Sierra de Atapuerca son financiadas por la Junta de Castilla y León. Las fotografías han sido realizadas por Javier Trueba y Uly Martín.

\section{BIBLIOGRAFÍA}

Alférez, F. (1985). Dos molares humanos procedentes del yacimiento del Pleistoceno medio de Pinilla del Valle (Madrid). Trabajos de Antropología, 19, 303.

Andrews, P. 1984. An alternative interpretation of characters used to define Homo erectus. En: P. Andrews \& J. L. Frazen (eds.) The Early Evolution of Man, Courier Forschungsinstitut Senckenberg, 69, 167-175.

Arsuaga, J. L., Martínez, I., Gracia, A., Carretero, J. M. and Carbonell, E. 1993. Three new human skulls from the Sima de los Huesos Middle Pleistocene site in Sierra de Atapuerca, Spain. Nature, 362, 534-537.

Bar-Yosef, O. and Pilbeam, D. 1993. Dating hominid remains. Nature, 366, 415.
Bischoff, J. L., Mora, R. and Julià, R. 1988. Uranium-series dating of the Mousterian occupation at Abric Romaní, Spain. Nature, 332, 68-70.

Bischoff, J. L., Soler, N., Maroto, J. and Julià, R. 1989. Abrupt Mousterian/Aurignacian boundary at c. $40 \mathrm{ka} \mathrm{bp:} \mathrm{accelerator}$ 14C dates from l'Arbreda Cave (Catalunya, Spain). Journal of Archaelogical Science, 16, 533-576.

Bischoff, J .L., Ludwig, K., García, J. F., Carbonell, E., Vaquero, M., Stafford, T. W., Jr. and Jull, A. J. T. 1994. Dating of the basal Aurignacian sandwich at Abric Romaní (Catalunya, Spain) by radiocarbon and uranium-series. Journal of Archaeological Science, 21, 541-551.

Blackwell, B. and Schwarz, H. P. 1986. U-series analysis of the lower travertine at Ehringsdorf, DDR. Quaternary Research, 25, 215-222.

Bowen, D. Q. and Sykes, G. A. 1994. How old is "Boxgrove man". Nature, 371, 751.

Bräuer, G. 1981. New evidence on the transitional period between Neanderthal and modern man. Journal of Human Evolution, 10, 467-474.

Carbonell, E. and Rodríguez, X. P. 1994. Early middle Pleistocene deposits and artefacts in the Gran Dolina site (TD4) of the 'Sierra de Atapuerca' (Burgos, Spain). Journal of Human Evolution, 26, 291-311.

Carbonell, E., Bermúdez de Castro, J. M., Arsuaga, J. L., Díez, J. C., Rosas, A., Cuenca-Bescós, G., Sala, R., Mosquera, M. and Rodríguez, X. P. (1995). Lower Pleistocene hominids and artefacts from Atapuerca-TD6 (Spain). Science, 269, 826-830.

Czarnetzki. 1991. Nouvelles découvertes d'un fragment de crâne d'un hominidé archaïque dans le Sud-Ouest de l'Allemagne. L'Anthropologie, 95, 103-111.

Etler, D. A. 1994. The Chinese Hominidae: New Finds, New Interpretations. Tesis, Universidad de California, Berkeley.

Frayer, D. 1992. Evolution at the European edge: Neanderthal and Upper Paleolithic relationships. Préhistoire Européenne, 2, 9-69.

Gabunia, L. and Vekua, A. 1995. A Plio-Pleistocene hominid from Dmanisi, East Georgia, Caucasus. Nature, 373, 509-512.

Gambier, D. 1989. Fossil hominids from the early Upper Palaeolithic (Aurignacian) of France. En: P. Mellars \& C. Stringer (eds.) The Human Revolution: 194-211. Edinburgh University Press, Edimburgo.

Gamble, C. 1994. Time for Boxgrove man. Nature, 369, 275-276.

Garralda, M. D. 1989. Upper Paleolithic human remains from El Castillo cave (Santander, Spain). En: Hominidae. Proceedings of the 2nd International Congress of Human Paleontology (Ed. G. Giacobini). Jaca Book, Milán, 479-482.

Howells, W. W. 1973. Cranial Variation in Man. Harvard University Press, Cambridge.

Howells, W. W. 1975. Neanderthal Man: Facts and figures. En: Paleoanthropology: Morphology and Paleoecology (Ed. R. H. Tuttle). Mouton, The Hague, 389-408.

Howells, W. W. 1980. Homo erectus-Who, when and where: a survey. Yearbook of Physical Antrhopology, 23, 1-23.

Hublin, J.-J. 1988. Les plus anciens représentants de la lignée prenéandertalienne. En: L'Homme de Néandertal 3 - L'anatomie (Ed. E. Trinkaus) Etudes et Recherques Archéologiques de l'Université de Liège, 30, 81-94.

Julià, R. and Bischoff, J. 1991. Radiometric dating of quaternary deposits and the hominid mandible of lake Banyolas, Spain. Journal of Archaeological Science, 18, 707-722. 
McDermott, F., Grün, R., Stringer, C. B. and Hawkesworth, C. J. 1993. Mass-spectrometric U-series dates for Israeli Neanderthal / early modern hominid sites. Nature, 363, 252-255.

Mercier, N., Valladas, H., Joron, J.-L., Reyss, J.-L., Lévêque, F. and Vandermeersch, B. 1991. Thermoluminiscence dating of late Neanderthal remains from Saint-Césaire. Nature, 351, 737-739.

Rak, Y. 1993. Morphological variation in Homo neanderthalensis and Homo sapiens in the Levant. A biogeographic model. En: Species, Species Concepts, and Primate Evolution (Eds. W. H. Kimbel \& L. B. Martin). Plenum Press, Nueva York, 523-536.

Rightmire, G. P. 1993. Variation among early Homo crania from Olduvai Gorge and the Koobi Fora region. American Journal of Physical Anthropology, 90, 1-33.

Roberts, M. B., Stringer, C. B. and Parfitt, S. A. 1994. A hominid tibia from Middle Pleistocene sediments at Boxgrove, UK. Nature, 369, 311-313.

Roebroeks, W. 1994. Updating the earliest occupation of Europe. Current Anthropology, 35, 301-305.

Stringer, C. B. 1992. The evolution of Homo sapiens. In: The Great Ideas Today. Encyclopedia Britannica, Chicago, 42-94.
Stringer, C. B. and Bräuer, G. 1994. Methods, misreading, and bias. American Anthropologist, 96, 416-424.

Stringer, C. and Gamble, C. 1993. In Search of the Neanderthals. Thames \& Hudson, Londres.

Swisher, C. C., Curtis, G. H., Jacob, T., Getty, A. G., Suprijo, A., and Widiasmoro. 1994. Age of the earliest known hominids in Java, Indonesia. Science, 263, 1118-1121.

Tattersall, I. 1986. Species recognition in Human Paleontology. Journal of Human Evolution, 15, 165-175.

Vandermeersch, B. 1984. A propos de la découverte du squelette néandertalien de Saint-Césaire. Bulletin et Mémoires de la Societé d'Anthropologie de Paris, t.1, série XIV, 191-196.

Vlček, E. 1991. L'homme fossile en Europe central. L'Anthropologie (Paris), 95, 409-472.

Wood, B. A. 1991. Koobi Fora Research Project. Volume 4. Hominid Cranial Remains. Clarendon Press, Oxford.

Manuscrito recibido: 24 de enero, 1995 Manuscrito aceptado: 30 de junio, 1995 